\title{
Cellular effects of hyperthermia: relevance to the minimum dose for thermal damage
}

\author{
JAMES R. LEPOCK* \\ Department of Medical Biophysics, University of Toronto, and Ontario Cancer \\ Institute, Princess Margaret Hospital, 610 University Avenue, Toronto, Ontario \\ M5G 2M9 Canada
}

(Received 1 June 2002; accepted 30 October 2002)

The specific mechanism of cell killing by hyperthermia is unknown, but the high activation energy of cell killing and other responses to hyperthermia suggest that protein denaturation is the rate-limiting step. Protein denaturation can be directly monitored by differential scanning calorimetry and in general there is a good correlation between protein denaturation and cellular response. Approximately 5\% denaturation is necessary for detectable killing. Protein denaturation leads to the aggregation of both denatured and native protein with multiple effects on cellular function.

Key words: Arrhenius plot, cell killing, protein denaturation, protein aggregation, thermotolerance, heat shock response.

\section{Introduction}

The effects of hyperthermia on mammalian cells are pleiotropic. In addition to multiple effects on cellular physiology, relatively short exposure to temperatures in excess of $40-41^{\circ} \mathrm{C}$ inhibit growth, are cytotoxic, alter signal transduction pathways, sensitize to other stresses such as ionizing radiation and many chemical agents, and induce a resistance, termed acquired thermotolerance, to subsequent heat treatment. This suggests that damage is not localized to a single target, but that multiple heatlabile targets are damaged and that the subsequent cellular responses occur throughout the cell. Extensive protein denaturation has been demonstrated to occur in mammalian cells during exposure to $40-45^{\circ} \mathrm{C}$ for moderate periods of time, numerous cellular functions damaged or inactivated have been identified, and much has been learned about how heat shock proteins (Hsp's) might be involved in acquired thermotolerance. However, at the present time the initial critical targets of heat damage have not been identified. Thus, the specific mechanisms of hyperthermic damage still are not known.

\section{Growth and killing at elevated temperatures}

\subsection{Direct effects of elevated temperature}

An increase in temperature results in increased translational, vibrational, and rotational motion of all molecules, including water, within cells, tissues, and organisms. All responses to hyperthermia must result from this increased motion. Increased motion results in more rapid reaction rates, resulting in both increased metabolism and transitions in cellular structures such as membranes and macromolecules such as protein and DNA. Increasing the rate of reactions is probably most

*e-mail: lepock@uhnres.utoronto.ca 


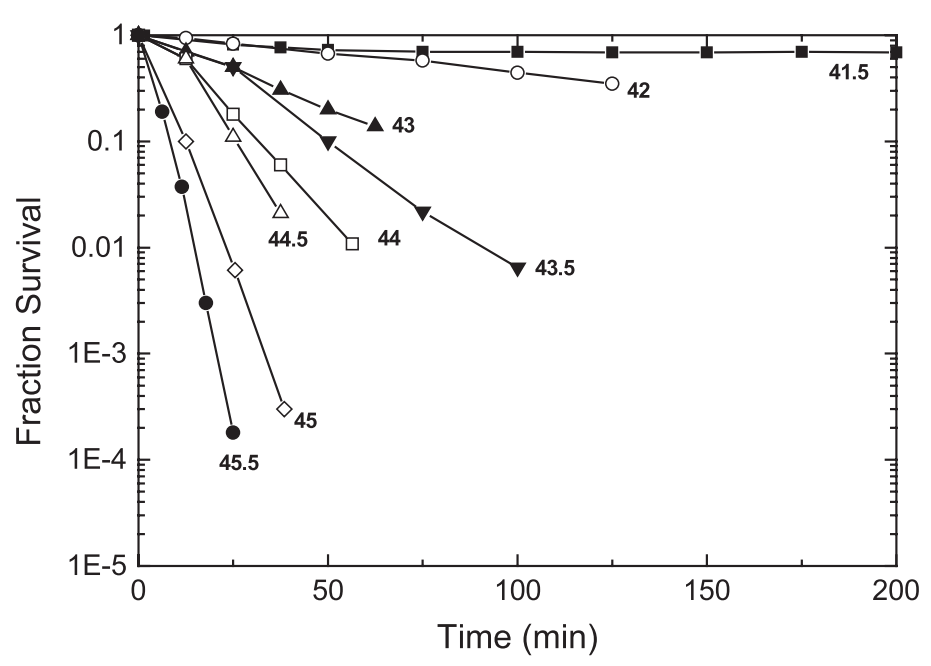

b

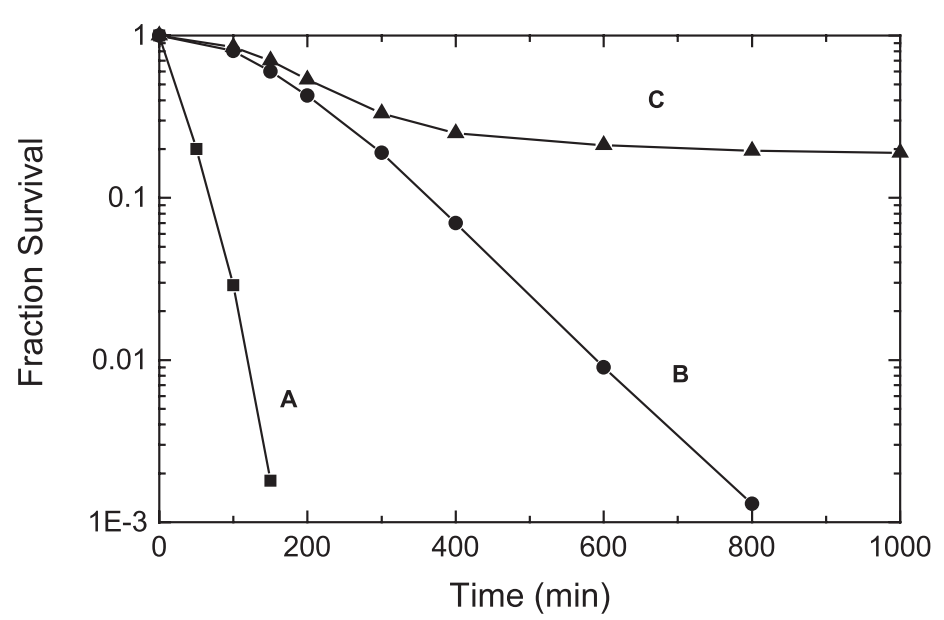

Figure 1(a). Fractional survival vs. time of exposure of Chinese hamster lung (CHL V79) cells from 41.5 to $45.5^{\circ} \mathrm{C}$. (b) Model survival curves: (A) at $43.5^{\circ} \mathrm{C}$, (B) at $41.5^{\circ} \mathrm{C}$ no thermotolerance, and $(\mathrm{C})$ at $41.5^{\circ} \mathrm{C}$ with thermotolerance.

damaging if it results in the unbalancing of related reactions, which is sometimes referred to as unbalanced metabolism. Metabolic and other enzymatic reactions are of relatively low activation energy (e.g. 3-20 kcal/mole) while transitions have a sharp temperature dependence resulting in high apparent activation energies (e.g. $100-200 \mathrm{kcal} / \mathrm{mole})$. A transition in a macromolecule is defined as a structural transformation from the ordered, native state to a more disordered state usually referred to as the unfolded or denatured state that is triggered by increasing temperature. 
Cellular responses governed by these molecular processes can be distinguished on the basis of their activation energies. Thermal damage appears to have a very high activation energy, in the range of 100-200 kcal/mole, and the rate limiting molecular mechanisms resulting in thermal damage must have a similar high activation energy, suggesting the involvement of a transition as the rate-limiting step (for a review see Lepock $^{1}$ ).

\subsection{Models of survival curves}

The most quantitative measurements of the response of mammalian cells to hyperthermia, which can be used to determine the temperature dependence of thermal damage, are survival assays which are usually based upon clonogenic capacity. Survival curves for Chinese hamster lung (CHL) V79 cells from 41.5 to $45.5^{\circ} \mathrm{C}$ are shown in figure $1(a)$. These curves are similar to many others obtained previously for other cell lines ${ }^{2}$ and are characterized by a shoulder and an exponential region. In addition, below a critical temperature, usually $42-43^{\circ} \mathrm{C}$ but dependent upon cell sensitivity, a plateau in survival occurs at longer heating times. This is thought to be indicative of the induction of thermotolerance during heating, usually referred to as chronic thermotolerance to distinguish it from acute thermotolerance (i.e., tolerance that develops at $37^{\circ} \mathrm{C}$ following acute heat shock). Chronic thermotolerance is observable for the $41.5^{\circ} \mathrm{C}$ curve at exposures greater than 200 minutes (not shown in Figure $1(a)$ ) and appears to occur during sufficient exposure to any temperature in excess of normal growth or body temperature. In addition, the slope of the exponential region is decreased by chronic thermotolerance below $42-43^{\circ} \mathrm{C}$. There is no convincing evidence that the mechanisms of acute and chronic thermotolerance differ, although there may be more than one mechanism of thermotolerance ${ }^{3}$.

Survival in the exponential region can be approximated by

$$
S(t)=S_{\mathrm{o}} e^{-k t}
$$

where $k$ is the rate of killing which corresponds to an inactivation rate, $S(t)$ is the number of surviving cells at time $t$, and $S_{\mathrm{o}}$ is the number of cells at $t=0$. This suggests that a direct correlation can be made with the inactivation of a molecular target or targets, since inactivation of enzymes by high temperature obeys similar kinetics ${ }^{4}$.

In the shoulder region, survival decreases less than exponentially for short times of exposure. If damage is proportional to dose, which for hyperthermia is dependent on both temperature and time of exposure, the presence of sublethal damage is implied, which can be interpreted in various ways depending on the model one uses. One interpretation is that this implies the existence of multiple targets or multiple copies of a target, all of which must be inactivated before death ensues.

$\mathrm{Hahn}^{5}$ developed a multitarget mode, using the above interpretation, similar to those used for killing by ionizing radiation based on the assumption of $n$ targets per cell, each requiring a critical kinetic energy $\left(S_{\mathrm{c}}\right)$ for inactivation. What constitutes a target is not defined. If the kinetic energy is distributed among the targets according to the Boltzman distribution, then the rate of inactivation of any target is given by

$$
k(T)=e^{-S_{\mathrm{c}} / R T}
$$

where $E_{\mathrm{c}}$ is the critical kinetic energy for that target. The probability $\left(P_{\mathrm{c}}\right)$ of a cell surviving an exposure for time $t$ to a temperature $T$ is 


$$
P_{\mathrm{c}}(S)=1-\left[1-(1-k)^{t}\right]^{n}
$$

This model can fit the usual hyperthermic survival curves with a shoulder and an exponential region and gives values of $n$ between 1 and 30. Since the molecular definition of a target is unclear, the exact meaning of $n$ is unclear. The simplest definition, that a target represents a single protein, is inconsistent with this model, since nearly all proteins are present in more than the few copies per cell implied by the small values of $n$ observed. Thus, it is more likely that the target is a complex structure.

Model survival curves were generated using the multitarget model and are shown in figure $1 b$. The value of the inactivation rate $k$ is $0.05 \mathrm{~min}^{-1}$ for curve A. This corresponds to the rate of killing of V79 cells at $43.5^{\circ} \mathrm{C}$. The shoulder was generated assuming a target number $(n)$ of 2 , which gives a shoulder (referred to as $D_{\mathrm{q}}$ ) of 13 minutes. Curve $\mathrm{B}$ corresponds to inactivation at $41.5^{\circ} \mathrm{C}\left(k \cong 0.01 \mathrm{~min}^{-1}\right)$ without the induction of thermotolerance. Curve $\mathrm{C}$ models a survival curve in which thermotolerance is induced in $20 \%$ of the cells yielding a resistant tail composed of cells that are 10 -fold more resistant to killing. The precise shape of the final survival curve is very sensitive to the values of $k$, thermotolerant fraction, and thermotolerance ratio. However, the model curve matches the actual survival curve measured at $41.5^{\circ} \mathrm{C}$ for V79 cells reasonably well and demonstrates that expression of thermotolerance in a fraction of the cells is sufficient to generate a resistant tail.

Thus, the rate of killing is highly dependent on the thermal history of the cells. Exposure to lower hyperthermic temperatures induces thermotolerence during heating, resulting in cells much more resistant to hyperthermia than the control cells. This is a simple demonstration that sensitivity to heat stress is not fixed, but is dependent upon numerous factors including previous heat exposures.

\subsection{Arrhenius plots of growth and killing}

Arrhenius plots of $k$ for killing in the hyperthermic region (figure 2) have a sharp bend at $42-43^{\circ} \mathrm{C}^{6}$, due to the induction of chronic thermotolerance during

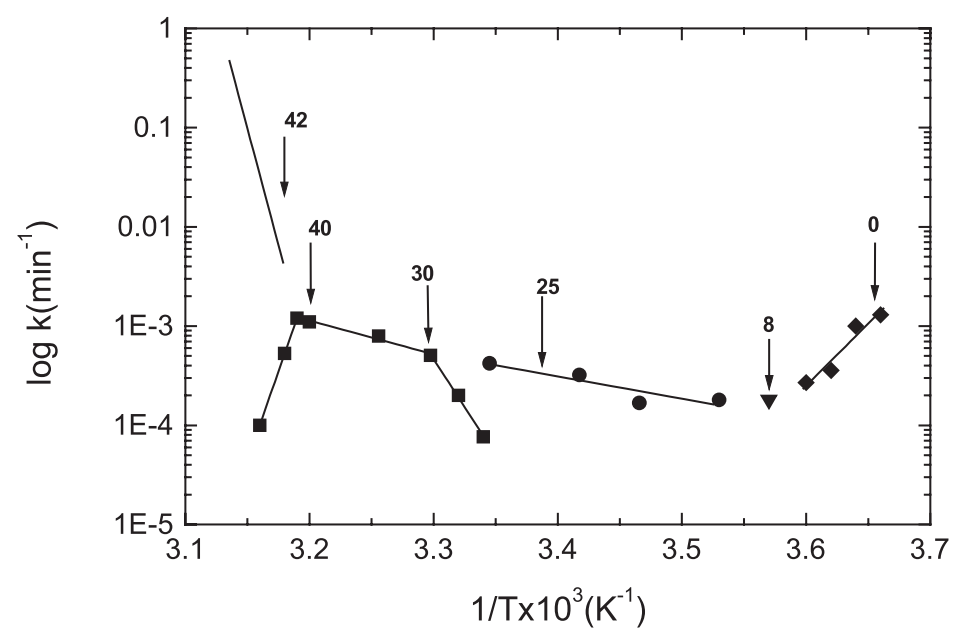

Figure 2. Arrhenius plots for growth $\left(30-40^{\circ} \mathrm{C}\right)$, hypothermic killing $\left(0-25^{\circ} \mathrm{C}\right)$, and hyperthermic killing $\left(42-45^{\circ} \mathrm{C}\right)$. 
the survival assay, but there is evidence they are linear for temperatures above this critical temperature to at least $57^{\circ} \mathrm{C}^{7}$. The linear relationship between $\ln k$ and $1 / T$ implies that the temperature dependence of the rate constant for killing can be approximated by

$$
k(T)=e^{A-E_{\mathrm{a}} / R T}
$$

where $E_{\mathrm{a}}$ is the slope and is referred to as the activation energy. Two interpretations of $E_{\mathrm{a}}$ are possible. The less mechanistic interpretation is that $E_{\mathrm{a}}$ is just a measure of the temperature dependence. A more specific interpretation relates cell killing to the inactivation of a molecular target: $E_{\mathrm{a}}$ represents the energy barrier for formation of the transition state of the critical target during the rate-limiting step of inactivation. Westra and Dewey ${ }^{2}$ have suggested that the very high value of $E_{\mathrm{a}}(150-200 \mathrm{kcal} /$ mole) for hyperthermic cell killing implies that protein denaturation is the rate-limiting step.

Evidence regarding the nature of thermal damage and the temperature range over which it occurs can be deduced from Arrhenius plots of killing and growth over the hyperthermic, normothermic, and hypothermic temperature ranges ${ }^{8}$. As shown in figure 2 , growth increases uniformly from $30-40^{\circ} \mathrm{C}$ for $\mathrm{V} 79$ cells with an activation energy of $18 \mathrm{kcal} / \mathrm{mole}$, implying that the rate of growth and division is limited by metabolic processes. The rate of growth decreases sharply above $40^{\circ} \mathrm{C}$. Measurements by Watanabe and Okada ${ }^{9}$ using L5178Y cells also show a maximum growth temperature near $40^{\circ} \mathrm{C}$. The onset of measurable killing over a few hours at $41.5-42^{\circ} \mathrm{C}$ in a number of mammalian cell lines indicates that a sharp transition from growth to killing at a few degrees above body temperature is a general characteristic of mammalian cells ${ }^{6}$. In addition, the theory proposed by Johnson et al. ${ }^{10}$ to explain the decrease in enzyme activity at elevated temperatures predicts a maximum in enzyme activity near the onset of the denaturation of that enzyme. This is similar to what is observed for cell growth.

In the hypothermic region, there is a sharp transition at $30^{\circ} \mathrm{C}$ from net growth to rapid killing. Hypothermic survival curves are similar to hyperthermic survival curves such as those shown in figure 1, with a shoulder and an exponential region, except that killing is two-to-three orders of magnitude slower. The rate of killing decreases from $25-8^{\circ} \mathrm{C}$ with an activation energy of $15 \mathrm{kcal} / \mathrm{mole}$, suggesting that metabolism, probably unbalanced metabolism, is the rate limiting step for hypothermic killing in this temperature range ${ }^{11}$.

Below $\sim 8^{\circ} \mathrm{C}$ there appears to be a dramatic shift in the mechanism of killing. The slope of the Arrhenius plot changes to an apparent 'negative activation energy' in the temperature range of $8-0^{\circ} \mathrm{C}$, which is indicative of a transition near $8^{\circ} \mathrm{C}$. A break in the Arrhenius plot for killing has been seen in several mammalian cell lines between $5-10^{\circ} \mathrm{C}^{8}$.

The Arrhenius curve in the hyperthermic region illustrates the normal properties of hyperthermic killing. For CHL V79 and other rodent cells, killing is first detectable at $40.5-41^{\circ} \mathrm{C}$, there is a bend in the curve at $42^{\circ} \mathrm{C}$ (barely visible in this figure because of the scale), and the activation energy is very high above this break (greater than $150 \mathrm{kcal} / \mathrm{mole}$ ). The high activation energy for killing is strong evidence that the rate limiting step is a transition in a critical target.

Thus, there are several critical temperatures for growth and killing of mammalian cells. These occur at near $8,25-30,40-41$, and $42-43^{\circ} \mathrm{C}$, and there is reason to believe 
that each involves a transition in some cellular component. Only growth and hypothermic killing from $8-25^{\circ} \mathrm{C}$ appear to be limited directly by metabolic events. Hypothermic killing below $8^{\circ} \mathrm{C}$ and hyperthermic killing above $41^{\circ} \mathrm{C}$ are induced by transitions. The critical temperature at $8^{\circ} \mathrm{C}$ is thought to be due to a lipid transition ${ }^{8}$, but nearly all the evidence indicates that the transition causing hyperthermic killing is due to protein denaturation ${ }^{1}$.

The Arrhenius analysis is based on killing being controlled by a molecular process with the same activation energy. Thus, thermal damage should have the same activation energy (ln $k$ vs $1 / T$ dependence) as cell killing. The bend on altered slope below $42-43^{\circ} \mathrm{C}$ is caused by thermotolerance. Thus, extrapolation of the region above $43^{\circ} \mathrm{C}$ to lower temperatures should give the rate of thermal damage at the molecular level at these temperatures in the absence of thermotolerance. Extrapolation of the curve for killing to $37^{\circ} \mathrm{C}$ gives a rate of killing of $0.094 \times 10^{-3} \mathrm{~min}^{-1}$ compared to a growth rate of $\sim 10^{-3} \mathrm{~min}^{-1}$ at $37^{\circ} \mathrm{C}$. Thus, significant thermal damage may occur even at the normal growth temperature, and if so cells have the capacity to endure or repair this damage. By comparing the generation time to the population doubling time, Johnson and Pavelec ${ }^{12}$ argued that there is a cell loss of $0.2 \% \mathrm{~h}^{-1}$ in Chinese Hamster Lung cells at $37^{\circ} \mathrm{C}$ due to what they term thermal noise. This analysis implies that thermal damage always occurs, even at $37^{\circ} \mathrm{C}$, and that the maximum temperature cells can endure is not the same as the maximum temperature at which damage does not occur, but is the maximum temperature at which cells can repair damage. This has implications for the minimum dose for thermal damage since exposure of cells or tissue to environmental conditions which reduce the ability to accumulate damage or inhibit the ability to repair damage will increase the amount of apparent thermal damage.

\section{Thermal damage}

\subsection{Transitions}

The high activation energy for cell killing implies that the rate limiting molecular process controlling killing has a similar high activation energy. This raises the questions as to what is the controlling molecular process and to whether or not other cellular processes besides killing also have a high activation energy. The rate constants for two other final responses for which good temperature dependent measurements have been made, thermal radiosensitization ${ }^{13}$ and teratogenisis ${ }^{14}$ also have high activation energies. Thus, complex cellular responses other than killing alone have high activation energies. Also the sharp decrease in oxygen consumption above $40-41^{\circ} \mathrm{C}$ implies that respiration is inhibited with a high activation energy ${ }^{15,16}$. This implicates a transition in a cellular macromolecule or structure as the rate-limiting step in these processes, since transitions are the only molecular processes with sufficiently high activation energies. This is an important implication suggesting that processes as dissimilar as inhibition of respiration, cell killing, and teratogenisis due to hyperthermia have similar mechanisms, even though the macromolecules and structures involved in each process are different.

Transitions occur in numerous cellular components. The question that must be answered is what is the transition (or transitions) that is the rate-limiting step for the above responses in mammalian cells? There are many potential targets. Transitions in the membrane lipid bilayer have been intensely investigated. They have a strong temperature dependence that is consistent with the high activation energy for killing. The most obvious lipid transition is the gel-to-liquid crystalline (melting) transition. 
The hypothesis has been presented that hyperthermic damage would result from the melting of normally solid domains present at $37^{\circ} \mathrm{C}$ when the temperature is increased. This is fundamentally different than the critical fluidity hypothesis, which postulates that death is caused merely by exceeding a maximum tolerable fluidity in the fluid, liquid crystalline regions of the membrane. There is no strong evidence for either gel lipid at $37^{\circ} \mathrm{C}$ or for a gel-to-liquid crystalline lipid transition above $37^{\circ} \mathrm{C}$ in mammalian cells, both of which are necessary conditions for death to be caused by a gel-to-liquid crystalline transition ${ }^{16}$.

Order-disorder transitions also occur in DNA and RNA. The main transitions in DNA are unlikely to play a role in killing since they are normally reversible and occur at high temperatures (in the range of $85-90^{\circ} \mathrm{C}$ ). However, localized melting of destabilized regions could be important. Structured RNA, such as double stranded regions, undergoes a melting transition similar to DNA. Possible RNA targets are tRNA and other forms of compact RNA such a rRNA and the small, nuclear ribonucleoprotein (snRNP) complexes. With the recent discoveries of the large number of enzymatic functions performed by RNA and its important role in many protein-RNA complexes such as ribosomes ${ }^{17}$, it must be considered as a potential target much like protein.

However, the most likely target for heat shock is protein. The denaturation or partial unfolding of proteins during heat exposure, resulting in damage due to the inactivation of crucial cellular functions or the disruption of cellular structures, is most consistent with the large body of experimental observations.

\subsection{Protein denaturation}

Direct evidence for the denaturation of proteins in mammalian cells is reviewed by Lepock ${ }^{1}$. The thermal stability of proteins is usually expressed in terms of the transition temperature for denaturation $T_{\mathrm{m}}$. Since this is the temperature at which half the protein denatures, and denaturation is both time and temperature dependent, considerable denaturation occurs at lower temperatures. Proteins appear to have transition widths of $10-12^{\circ} \mathrm{C}^{18}$, implying that denaturation first occurs at $5-6^{\circ} \mathrm{C}$ below $T_{\mathrm{m}}$. A summary of some important results concerning protein denaturation in cells follows (more details are given in Lepock ${ }^{1}$ ):

(1) Four major transitions occur in human enythrocytes with the following identifications: spectrin $\left(T_{\mathrm{m}}=49^{\circ} \mathrm{C}\right)$, membrane skeleton bands $2.1,4.1$, and $4.2\left(T_{\mathrm{m}}=55^{\circ} \mathrm{C}\right)$, transmembrane portion of band $\mathrm{C}\left(T_{\mathrm{m}}=65^{\circ} \mathrm{C}\right)$, and hemoglobin $\left(T_{\mathrm{m}}=72^{\circ} \mathrm{C}\right)$. The morphological changes occurring in enythrocytes during heating at temperatures above $43^{\circ} \mathrm{C}$ appear to be due to the denaturation of spectrin.

(2) A number of mammalian cell lines (the rodent lines CHL V79, CHO, L929, and $3 \mathrm{~T} 3$ and human lines HeLa and A549) have five major transitions with the $T_{\mathrm{m}}$ of the lowest transition equal to $50^{\circ} \mathrm{C}$. The important parameter is the onset temperature of denaturation which is $\sim 40^{\circ} \mathrm{C}$ in rodent cells and $41-$ $42^{\circ} \mathrm{C}$ in human cells when both types of cells are grown at $37^{\circ} \mathrm{C}$. This is the lowest temperature of detectable protein denaturation using differential scanning calorimetry (DSC).

(3) The onset for protein denaturation in microsomal membranes, mitochrondria, cytosol, nuclei and nuclear matrices isolated from rat hepatocytes is 
approximately $40^{\circ} \mathrm{C}$. Thus, all major components of the cell suffer some protein denaturation above this temperature.

(4) A comparison of fractional protein denaturation vs. cell killing in CHL V79 cells indicates that little or no killing occurs until $\sim 5 \%$ of total cellular protein is denatured and at $10 \%$ denaturation $\sim 95 \%$ of V79 cells are killed.

(5) The cellular hyperthermic sensitizers methanol, ethanol, propanol and butanol increase protein denaturation in proportion to their sensitization. The cellular protectors glycerol and $D_{2} 0$ also protect cellular proteins from denaturation. In addition, a number of thiol specific oxidative agents sensitize cells to hyperthermia, induce a heat shock response, and sensitize proteins to denaturation (reviewed by Freeman et al. (19)).

(6) Thermotolerant V79 cells have a higher onset for denaturation $\left(\Delta T_{\mathrm{m}} \sim 1.3^{\circ} \mathrm{C}\right)$ than control cells.

Thus, protein denaturation occurs in mammalian cells at temperatures in excess of $40-42^{\circ} \mathrm{C}$ and possibly at lower temperatures. Measurable protein denaturation can occur at $37^{\circ} \mathrm{C}$ during exposure to compounds and conditions that exert a proteotoxic stress. There are two general effects of protein denaturation that one would expect to be particularly harmful to cells: direct inactivation of protein function and disruption of complex structures. Inactivation of enzyme activity, membrane receptors, and ion transporters has been shown to occur during hyperthermia ${ }^{20}$. Death may be caused by damage of this kind; however, a more difficult damage to repair may be structural damage. This can consist of membrane permeability changes, depolymerization of complex structures (e.g. disruption of cytoskeletal elements), and aggregation (e.g. aggregation of membrane proteins and binding of proteins to the nuclear matrix and other cytoskeletal structures). Damage of this type can have pleiotrophic effects on cellular physiology and may ultimately be the cause of death. In addition, damage to the nucleus is consistent with the strong radiosensitization and teratogenesis effects of hyperthermia. Teratogenesis is extremely sensitive to elevated temperature, and the suggestion has been made that teratogenic effects may be observed after long exposures at temperature elevations of only $1.5-2.0^{\circ} \mathrm{C}$ above normal core temperatures in experimental mammals such as guinea pigs and rats ${ }^{14}$. This implies the cellular targets for teratogenesis are extremely heat sensitive. The effects of hyperthermia on cell function are discussed in $\S \mathrm{V}$.

\section{Thermotolerance and the heat shock response}

\subsection{Heat shock response}

The term heat shock response is usually used to refer to the induction of heat shock proteins (Hsps) by heat shock or hyperthermia. However, in a broader sense the heat shock response encompasses all the responses by cells and organisms to a heat shock. The primary determinant of the sensitivity of an organism or cells to hyperthermia is intrinsic protein stability, which is determined by amino acid sequence. For example, glyceraldehyde-3-phosphate dehydrogenase (GPDH) from the mesophile Bacillus coagulans is rapidly inactivated at temperatures above $55^{\circ} \mathrm{C}$, while GPDH from the thermophile Bacillus stearothermophilus is stable to $80^{\circ} \mathrm{C}^{21}$. The difference in stability is due to 28 amino acid residue differences between the two proteins. Five ala-to-pro substitutions in the thermophilic enzyme are thought to have a major effect on stability ${ }^{21}$. Three different amino acid changes in kanamycin 
nucleotidyl transferase can cause either a $9^{\circ} \mathrm{C}$ increase or decrease in the inactivation temperature $^{22}$. Thus, intrinsic protein stability is sufficient to account for vast differences in cellular resistance to hyperthermia.

However, numerous factors and environmental conditions, such as ionic composition and $\mathrm{pH}$, modulate cellular sensitivity. One important factor is the amount of cellular Hsps, which are the primary, if not sole, cause of thermotolerance. Thermotolerance is defined as the increased thermal resistance that develops after a heat shock during exposure to slightly elevated temperatures, or following certain chemical treatments, in mammalian cells. Thermotolerance is important since, as discussed in $\S$ II, it is a major factor influencing the sensitivity of cells to hyperthermia. Several excellent reviews discuss general aspects of heat shock proteins as molecular chaperones ${ }^{23}$, the role of Hsps in protein folding ${ }^{24,25}$, protein quality control $^{26}$, and the response of cells and organisms to stress and death ${ }^{27,28}$.

In mammals, activation of the transcription factor HSF1 leads to the induction of all stress-inducible proteins (i.e. those whose promoters contain a heat shock element (HSE)). Three HSFs have been characterized in humans, but HSF1 has the principal role in the induction of stress-induced genes. It appears that HSF1 is maintained in an inactive form through interactions with Hsp 90 and possibly Hsp 70. Generation of denatured protein during heat shock supplies additional substrate for Hsps and shifts the equilibrium of HSF1 from the bound to unbound form. The active form of HSF1 is the phosphorylated trimer which binds to the HSE and activates transcription of heat shock genes. Overall, there are multiple steps in HSF1 activation and HSP induction ${ }^{29}$. Thus, the synthesis of Hsps is a direct response to thermal damage in the form of denatured protein. Detection of Hsp induction or activation of HSF1 is an indication of the formation of denatured protein and the presence of thermal damage.

Hsp induction is observed after acute exposure to elevated temperature but also during continuous exposure to temperatures only slightly elevated above normal growth temperature. For example, Hsp synthesis is observed in HeLa cells at temperatures of $39^{\circ} \mathrm{C}$ and above ${ }^{30}$. In addition, injection of denatured protein, specifically denatured protein that aggregates, is sufficient to induce the synthesis of $\mathrm{Hsps}^{31}$.

These observations suggest that protein denaturation occurs at temperatures only a few degrees above $37^{\circ} \mathrm{C}$, although the amount of denaturation is probably low since growth is not affected. In addition, after incubation at $4^{\circ} \mathrm{C}$, which probably allows some adaptation to low temperatures, Hsp synthesis can be detected after return to $37^{\circ} \mathrm{C}^{32}$. This results from some loss of stabilizing factors during low temperature incubation, probably because of some degree of adaptation to lower temperatures, and is consistent with only a small increase in temperature needed for thermal damage. These results are also consistent with the direct detection of protein denaturation by $\mathrm{DSC}^{1}$.

\subsection{Thermotolerance}

As described in $\S \mathrm{II}$, thermotolerance is defined as the increase in cellular resistance to hyperthermia occurring after either a brief exposure to $42-45^{\circ} \mathrm{C}$ followed by recovery at $37^{\circ} \mathrm{C}$ (acute thermotolerance) or continuous exposure to longer periods at non-lethal temperatures of $38-40^{\circ} \mathrm{C}$ (chronic thermotolerance). Thermotolerance can also be induced by a number of proteotoxic chemicals and stresses ${ }^{19}$. A good correlation exists between increased synthesis of Hsps and what is referred to as 
protein synthesis dependent thermotolerance (for a review see Landry et $a l{ }^{30}$ ). Under some conditions thermotolerance can develop without the synthesis of additional Hsps, and this is referred to as protein synthesis independent thermotolerance 3,33 . However, Hsps could still be responsible for all forms of thermotolerance, even in the absence of additional Hsp synthesis, if constitutive Hsps are mobilized or activated by heat shock. In yeast and microorganisms, a thermotolerant state occurs following synthesis of threalose and glycerol, but mammalian cells do not use these compounds. Thus, Hsps are the only known mechanism for thermotolerance in mammals.

\subsection{Heat shock proteins}

The known function of heat shock proteins have been described in a number of reviews ${ }^{23-28}$. Briefly, they function by binding to denatured protein or partially unfolded intermediates to block aggregation and allow refolding to occur. Multiple cycles of binding and release of chaperones such as GroEL may occur before folding through a productive pathway occurs. Of relevance for heat exposure is the mechanism by which Hsps modulate thermal sensitivity. This appears to occur by a mechanism similar to that for assisted protein folding ${ }^{24,25}$. Hsps bind to newly denatured protein, thus blocking aggregation and allowing refolding by the mechanism described above.

\section{Alterations in cell structure and function}

\subsection{Chromosomal aberrations and mitotic dysunction}

The only cellular lesions which have been demonstrated to be closely associated with cell killing are the chromatid-type aberrations produced when cells are heated in $\mathrm{S}$ phase $\mathrm{s}^{34,35}$ and centrosomal damage when CHO cells are heated in G1 phase ${ }^{36}$. Mammalian cells are most sensitive when heated during mitosis, second most sensitive when heated in $\mathrm{S}$ phase, and much more resistant when heated in $\mathrm{G}_{1}{ }^{35}$. The average of one aberration per cell produced in $\mathrm{S}$ phase for a fractional killing of $63 \%$ $(1-1 / e)$ is sufficient to cause killing. Heat does not appear to directly induce DNA double strand breaks, which are required for the formation of chromosomal aberrations, but breaks probably occur during synthesis or are due to misrepair ${ }^{35}$. Related to aberration formation may be the observations that heat shock inhibits the formation of replicons, reduces the rate of replication fork displacement, and increases the amount of single-stranded DNA in the replicating regions ${ }^{35}$.

In addition, for at least $\mathrm{CHO}$ cells heated in G1, centrosomes are damaged which leads to mitotic dysfunction which is manifested by death when cells enter the next mitosis ${ }^{36}$. Aggregated protein appears to be associated with centrosomes isolated from heated cells, which may interfere with their proper function during mitosis. There is also a large increase in insoluble, aggregated protein in the nucleus following heat shock, which may interfere with replication leading to aberrations ${ }^{37}$. Both of these demonstrated mechanisms of thermal killing may involve protein aggregation. The formation of insoluble aggregates in the cell is discussed in more detail below.

\subsection{Plasma membrane}

5.2.1. Lipid properties. An increase in lipid fluidity or a melting of gel lipid regions during exposure to hyperthermia has been thought a likely target, since the very early observations that thermophilic microorganisms have a higher content of saturated and long chain lipids (for a review see Amelunxen and Murdock ${ }^{38}$ ). 
However, detailed studies relating lipid phase transitions to the maximum growth temperature indicate that membrane lipid fluidity is not the limiting factor for hyperthermia killing in microorganisms (for reviews see McElhaney ${ }^{39}$ and Lepock ${ }^{16}$ ). The situation with mammalian cells is more complex with some studies showing a small effect of alterations in membrane fluidity on hyperthermic sensitivity ${ }^{16,20}$. Although, membrane fluidity might modulate the response of cells to hyperthermia, it does not appear to be the main determinant of killing.

5.2.2. Membrane transport. There have been suggestions that increases in ion permeability (i.e. $\mathrm{Na}^{+}, \mathrm{K}^{+}$and especially $\mathrm{Ca}^{2+}$ ) and inhibition of amino acid transport play a role in cell killing. These originated from studies which showed a net $\mathrm{K}^{+}$efflux and $\mathrm{Na}^{+}$influx following heating (for review see Lepock ${ }^{16}$ ). However, other studies have shown that even after severe heat treatments $\left(45^{\circ} \mathrm{C}\right.$ for $\left.30 \mathrm{~min}\right)$ cells appear able to maintain normal ion gradients for at least $10-16 \mathrm{~h}^{35}$. At this time, a small fraction of cells lose the ability to maintain ion gradients as they die a metabolic death. This total loss of ion permeability by the fraction of dying cells probably accounts for the positive observations. Thus, the initial lesion causing death is not a major loss of ion impermeability. Still there are reports of changes in membrane potential at modest heat treatments ${ }^{40,41}$, which could be due to fairly minor changes in ion permeability which are undetectable by other means. The functional implications of these possible changes are unknown, but they appear unrelated to killing ${ }^{42}$.

5.2.3. Membrane receptors. A number of interesting observations have been made relating to damage to receptors and impairment of ligand binding. These are important since these alterations in receptor function could be manifested as changes in signal transduction pathways, potentially at lower, sub-lethal temperatures; however, this has not been investigated in detail.

Stevenson et $a l^{43}$ have observed a decrease in Con-A-induced capping, that correlated with lethality of HA-1 $\mathrm{CHO}$ cells after prior exposure to temperatures of $43^{\circ} \mathrm{C}$ and higher. An inhibition of capping has also been observed in mouse $\mathrm{B}$ lymphocytes after heating which correlated with an enhancement of $\mathrm{Ab}-\mathrm{C}$ cytotoxicity $^{44}$. Calderwood and $\mathrm{Hahn}^{45}$ have reported a detailed investigation of the effects of hyperthermia upon insulin binding to HA-1 CHO cells. Heat treatment resulted in a dose-dependent decrease in insulin binding due to a loss of insulin receptor, not reduced affinity of the receptor for insulin. Cells made thermotolerant were not only more resistant to killing, but also to receptor loss. Inhibition of insulin binding appeared to be due to damage to the receptor itself or to the membrane, not to indirect, energy-dependent processes such as internalization.

The binding of epidermal growth fact (EGF) to rat-1 cells is inhibited, in a dose dependent fashion, by heating at $45^{\circ} \mathrm{C}^{47}$. The affinity of the EGF receptor, rather than number of receptors as for insulin, is reduced. Receptor-mediated endocytosis of EGF is not affected, while the degradation of internalized EGF by lysosomes was inhibited, implying possible damage to the lysosome.

The binding of antibody (anti-H-2 $\mathrm{K}^{\mathrm{k}}$ and anti-H-2 $\mathrm{K}^{\mathrm{b}}$ ) to the cell surface histocompatibility antigens of murine lymphoma cells is also inhibited by hyperthermia ${ }^{47}$. As for insulin, but in contrast to EGF, the decreased antibody binding appears to be due to decreased receptor number, not reduced affinity. The effect of hyperthermia on the ligand binding and distribution of the disparate receptors investigated is 
striking. This can only be accounted for by each receptor being individually sensitive to temperatures above $42-43^{\circ} \mathrm{C}$ or by a temperature-induced, general alteration in membrane structure above $42-43^{\circ} \mathrm{C}$ that interferes with the function of all membrane receptors.

\subsection{Cytoskeleton}

Some of the most apparent manifestations of thermal damage at the cellular level are morphological changes such as cell rounding and blebbing ${ }^{48}$. The degree of blebbing correlates well with cell killing ${ }^{49}$. The morphological changes appear to implicate the plasma membrane; however, cellular morphology is primarily determined by the cytoskeletal system, which is known to be damaged by hyperthermia (for review see Coss and Linnemans ${ }^{50}$ ). Microtubules, microfilaments, and intermediate filaments all suffer damage and varying degrees of depolymerization during heating, although the specific mechanisms of damage are unknown ${ }^{50}$. In addition, the consequences of cytoskeletal damage, particularly with regard to cell killing, are poorly understood.

\subsection{Protein aggregation and insolubilization}

Nearly all proteins aggregate following thermal denaturation in vitro. There is considerable evidence that the same occurs in vivo. All present assays for intracellular aggregation are based on the formation of non-extractable, insoluble aggregates ${ }^{51}$. Numerous studies have shown that the amount of insoluble protein in the nucleus increases following heat shock (for a review see Roti Roti and Laszlo ${ }^{52}$ ). Several enzymes involved in DNA replication and repair, and several nuclear oncoproteins and proto-oncoproteins have reduced extractability following heat shock. Much of the insoluble protein appears bound to the nuclear matrix. In addition to aggregation of nuclear proteins, cytoplasmic proteins also aggregate, although the aggregates are much weaker and more easily disrupted.

An important characteristic of these insoluble aggregates is that they contain not only denatured protein but also native proteins. Many protein that aggregate in the cell still retain activity ${ }^{51}$. Thus, it appears that the thermally denatured protein acts as a nucleation site, probably due to exposure of hydrophobic residues, for the binding of native protein. This may interfere with the function of these proteins and, hence, be an important form of damage.

Protein aggregation may be important even at very mild exposures, since it can happen at low temperatures. For example, large aggregates, containing but not limited to protein kinase $\mathrm{C}$ and spectrin, form in mammalian lymphocytes at $39^{\circ} \mathrm{C}^{53}$.

\subsection{Nuclear effects}

Hyperthermia is a potent sensitizer to ionizing radiation (for a recent review see Kampinga and Dikomey ${ }^{54}$ ). Although the precise mechanism of thermal radiosensitization is unknown, there is considerable evidence that it is due to the inhibition of repair of DNA damage caused by radiation. There is some evidence that the main contribution may come from inhibition of the religation step of base excision repair ${ }^{54}$. There may be similarities between thermal radiosensitization and heat killing of S phase cells, since both result in increased levels of chromosomal aberrations. Indirect and correlative data suggest that protein aggregation onto the nuclear matrix, resulting in reduced accessibility of damaged DNA to repair complexes, 
may play an important role in both thermal radiosensitization and cell killing, particularly in $\mathrm{S}$ phase $\mathrm{e}^{37,54}$.

For human cells heated at high temperatures $\left(T \geq 43^{\circ} \mathrm{C}\right)$, both cell killing and thermal radiosensitization have a similar temperature dependence and similar induction times ${ }^{55}$. However, at $41^{\circ} \mathrm{C}$ and lower radiosensitization can occur with minimal or no cell killing. Thus, radiosensitization can be a sub-lethal effect and occur at mild hyperthermic temperatures, again illustrating the interaction of hyperthermia and other damaging agents. Interactions are important for the final level of cytotoxicity; heat damage influences the amount of damage from other forms of stress. The overall level of toxicity is a complex function of the initial cellular state and simultaneous exposure to other harmful conditions.

\section{Conclusions}

(1) In culture, both human and rodent cells are able to grow and divide continuously at temperatures below $40-41^{\circ} \mathrm{C}$, although adaptation to a more thermotolerant state occurs during exposure to any temperature above the normal growth temperature.

(2) Cell killing commences above the maximum growth temperature with a strong temperature dependence, illustrated by a high activation energy of $100-200 \mathrm{kcal} / \mathrm{mole}$, implicating a transition in a cellular macromolecule or structure as the rate limiting step in killing.

(3) Protein denaturation is probably the rate limiting step for hyperthermic cell killing and for any other thermal effect with a high activation energy.

(4) The formation of chromosomal aberrations is sufficient to account for hyperthermic cell killing in $\mathrm{S}$ phase cells. This indicates the formation or misrepair of DNA damage.

(5) Hyperthermia sensitizes to a number of other stresses, including ionizing radiation. Thus, hyperthermia is most damaging when combined with other stresses.

(6) Thermal sensitization to ionizing radiation involves an inhibition of repair of DNA damage. This suggests that a similar sensitization to other genotoxic agents by hyperthermia may exist, which has been observed for some chemotherapeutic drugs.

\section{References}

1. Lepock, JR, Protein denaturation during heat shock. Adv Molec Cell Biol. 1997; 19: 223259.

2. Westra A, Dewey, WC. Variation in sensitivity to heat shock during the cell cycle of chinese hamster cells in vitro. Int J. Radiat Biol. 1971; 19: 467-477.

3. Laszlo A. Evidence for two states of thermotolerance in mammalian cell. Int $J$. Hyperthermia 1988; 4: 353-358.

4. Mozhaev VV, Martinek K. Inactivation and reactivation of proteins (enzymes). Enzyme Microb Technol. 1982; 4: 299-309.

5. Hahn, GM. Hyperthermia and Cancer. New York: Plenum Press, pp. 90-94, 1982.

6. Leith JT, Miller RC, Gerner EG, Boone MLM. Hyperthermic potentiation: biological aspects and applications to radiation therapy. Cancer 1977; 39: 766-779.

7. Borrelli MJ, Thompson LL, Cain CA, Dewey WC. Time-temperature analysis of cell killing: $\mathrm{BHK}$ cells heated at temperatures in the range of $43.5^{\circ} \mathrm{C}$ to $57^{\circ} \mathrm{C}$. Int J. Radiat Oncology Biol Phys. 1990; 19: 389-399. 
8. Kruuv J, Glofcheski D. Cheng KH, Cambpell SD, Al-Qysi HMA, Nolan WT, Lepock JR. J. Cell Physiol. 1983; 115: 179-185.

9. Wanatabe I, Okada S. Stationary phase of cultured mammalian cells (L5178Y). J. Cell Biol. 1967; 35: 285-94.

10. Johnson FH, Eyring H, Stover BJ. The theory of rate processes in biology and medicine. New York: John Wiley and Sons, Inc, 1974.

11. Hochachka, PW. Defense strategies against hypoxia and hypothermia. Science 1986; 31: 234-241.

12. Johnson HA, Pavelec M. Thermal noise in cells: A cause of spontaneous loss of cell junction. Am J. Pathol. 1972; 69: 119-130.

13. Spiro IJ, Denman DL, Dewey WC. Effect of hyperthermia on CHO DNA polymerases alpha and beta. Radiat. Res. 1982; 89: 134-149.

14. Miller MW, Nyborg WL, Dewey WC, Edwards MJ, Abramowicz JS, and Brayman AA. Hyperthermic teratogenicity, thermal dose and diagnostic ultrasound during pregnancy: implications of new standards on tissue heating. Int. J Hyperthermia 2002; 18: 361-384.

15. Dickson JA, Shah DM. The effects of hyperthermia $\left(42^{\circ} \mathrm{C}\right)$ on the biochemistry and growth of a malignant cell line. Eur J. Cancer 1972; 8: 561-571.

16. Lepock JR. 1987 Membrane lipids and proteins. In: Henle, KJ, ed. Thermotolerance. Volume II Mechanisms of Heat Resistance. Boca Raton, FL: CRC Press, 1987, pp. 47-82.

17. Wimberly BT, Brodersen DE, Clemons WM, Morgan-Warren RJ, Carter AP, Vonrheim, C, Hartsch T, Ramakrishan V. Structure of the 30S ribosomal subunit. Nature 2001; 407: 327-339.

18. Privalov PL, Khechinashvili NN. A thermodynamica approach to the stabilization of globular protein structure. A calorimetric study. J. Mol Biol. 1974; 86: 665-684.

19. Freeman ML, Borrelli MJ, Meredith MJ, Lepock JR. On the path to the heat shock response. Free Radical Biol Med. 1999; 26: 737-745.

20. Laszlo A. The effects of hyperthermia on mammalian cell structure and function. Cell Prolif. 1992; 25: 59-87.

21. Tesfay HS, Amelunxen RE, Goldberg ID. Nucleotide sequences of genes encoding heatstable and heat-labile glyceraldehyde-3-phosphate dehydrogenases; anino acid sequence and protein thermostability. Gene 1989; 82: 237-248.

22. Matsumura M, Yasumura S, Shuichi A, Cummulative effect of intragenic amino-acid replacements on the thermostability of a protein. Nature 1986; 323: 356-358.

23. Becker J, Craig EA. Heat shock proteins as molecular chaperones. Eur J. Biochem. 1994; 219: 11-23.

24. Frydman F. Folding of newly translated proteins In Vivo: The role of molecular chaperones. Annu Rev Biochem 2001; 70: 603-647.

25. Hartl FU, Hayer-Hartl M. Molecular chaperones in the cytosol: from nascent chain to folded protein. Science 2002; 295: 1852-1858.

26. Gottesman S, Wickner S, Maurizi MR. Protein quality control: triage by chaperones and proteases. Genes Develop. 1997; 11: 815-823.

27. Jolly C, Morimoto RI. Role of heat shock response and molecular chaperones in oncogenesis an cell death. J. Natl Cancer Inst. 2000; 92: 1564-1572.

28. Kregel KC. Heat shock proteins: modifying factors in physiological stress responses and acquired thermotolerance. J. Appl Physiol. 2002; 92: 2177-2186.

29. Zuo JR, Rungger D, Voellmy R. Multiple layers of regulation of human heat shock transcription factor 1. Mol Cell Biol. 1995; 15: 4309-4430.

30. Landry J, Lamarche S, Cretien P. Heat shock proteins: a lead to the understanding of cell thermotolerance. In: Henle, KJ, ed., Thermotolerance, Volume I, Boca Raton, FL: CRC Press, 1987, 145-177.

31. Mifflin LC, Cohen RE. Characterization of denatured protein inducers of the heat shock (stress) response in xenopus laevis oocytes. J. Biol Chem. 1994; 269: 15 710-15717.

32. Liu AY, Bian H, Huang LE, Lee Y K. Transient cold shock induces the heat shock response upon recovery at 37 degrees C in human cells. J. Biol Chem. 1994; 269: $14768-14775$.

33. Lee YJ, Dewey WC. Protection of chinese hamster ovary cells from hyperthermic killing by cyclohexamide or puromycin. Radiat Res. 1986; 106: 98-110. 
34. Dewey WC, Westra A, Miller HH, Nagasawa H. Heat-induced lethality and chromosomal damage in synchronized chinese hamster cells treated with 5-bromodeoxyuridine. Int J. Radiat Bio. 1971; 20: 505-520.

35. Dewey WC. The search for critical targets damaged by heat. Radiat Res. 1989; 120: 191204.

36. Vidair CA, Doxsey SJ, Dewey WC. Heat shock alters centrosome organization leading to mitotic dysfunction and cell death. J. Cell Physiol. 1993; 154: 443-455.

37. VanderWaal, RP, Wright WD, Roti Roti JL. The effects of heat-shock on nuclear matrixassociated DNA replication complexes. Crit Rev Eukaryot Gene Expr. 1999; 9: 363-371.

38. Amelunxen RE. Murdock AL. Mechanisms of thermophily. CRC Crit Rev Microbiol. 1978; 6: 343-372.

39. McElhaney RN. Effects of membrane lipids on transport and enzymatic activities. Curr Top Membr Transport 1982; 17: 317-342.

40. Mikkelsen RB, Koch B. Thermosensitivity of the membrane potential of normal and simian virus transformed hamster lymphocytes. Cancer Res. 1981; 41: 209-215.

41. Mikkelsen RB, Asher CR. Effects of hyperthermia on the membrane potential and $\mathrm{Na}^{+}$ transport of V79 fibroblasts. J. Cell Physiol. 1990: 144: 216-221.

42. Borrelli MJ, Rausch CM. Microelectrode measurements of the transmembrane potential in baby hamster kidney, chinese hamster ovary, NG108-15 neuroblastoma and swiss 3T3 cells at 37.0 or $43.0^{\circ} \mathrm{C}$. Int. J Hyperthermia 1991; 7: 827-838.

43. Stevenson MA, Minton KW, Hahn GM. Survival and concanavalin-A-induced capping in CHO fibroblasts after exposure to hyperthermia, ethanol, and $\mathrm{X}$ irradiation. Radiat Res. 1981; 86: 467-478.

44. Sultan MF, Tompkins WA, Cain CA. Hyperthermia enhancement of antibody-complement cytotoxicity against normal mouse $\mathrm{B}$ lymphocytes and its relation to capping. Radiat Res. 1983; 96: 251-260.

45. Calderwood SK, Hahn GM. Thermal sensitivity and resistance of insulin-receptor binding. Biochim Biophys Acta. 1983; 756: 1-12.

46. Magun BE, Fennie CW. Effects of hyperthermia on binding, internalization, and degradation of epidermal growth factor. Radiat Res. 1981; 86: 133-146.

47. Medhi SQ, Recktenwald DJ, Smith LM, Li GC, Armour EP, Hahn GM. The effect of hyperthermia on murine cell surface histocompatibility antigens. Cancer Res. 1984; 44: 3394-3397.

48. Lin PS. Cytoskeleton and modified heat sensitivity. In: Henle, KJ, ed. Thermotolerence. Volume II mechanisms of heat resistance. Boca Raton, FL: CRC Press, Inc. 1987, pp. 83 104.

49. Borrelli MJ, Wong RSL, Dewey WC. A direct correlation between hyperthermia-induced membrane blebbing and survival in synchronous G1 CHO cells. J. Cell Physiol. 1986; 126: 180-190.

50. Coss RA. Linnemans WAM. The effects of hyperthermia on the cytoskeleton: A review. Int J. Hyperthermia 1996; 12: 173-196.

51. Nguyen VT, Morange M, Bensaude O. Protein denaturation during heat shock and related stress. Escherichia coli Beta Galactosidase and Photinus pyralis Luciferase Inactivation in Mouse Cells. J. Biol Chem. 1989; 264: 10487-10 492.

52. Roti Roti, JL, Laszlo A. 1988. The effects of hyperthermia on cellular macromolecules. In: Urano $\mathrm{M}$ and Douple EB, eds, Hyperthermia and Oncology, Vol. 1, Zeist, The Netherlands: VSP, 1988, 13-56.

53. Wang XY, Ostberg JR, Repasky EA. Effect of fever-like whole-body hyperthermia on lymphocyte spectrin distribution, protein kinase $\mathrm{C}$ activity, and uropod formation. J. Immunol. 1999; 162: 3378-3387.

54. Kampinga HH, Dikomey E. Hyperthermic radiosensitization: mode of action and clinical relevance. Int J. Radiat Biol. 2001; 77: 399-408.

55. Xu M, Wright WD, Higashikubo R, Wang LL, Roti Roti, JL. Thermal radiosensitization of human tumor cell lines with different sensitivities to $41.1^{\circ}$ C. Int J. Hyperthermia 1999; 15: 279-290. 